\title{
Pentosan polysulfate ameliorates apoptosis and inflammation by suppressing activation of the p38 MAPK pathway in high glucose-treated $H K-2$ cells
}

\author{
PING CHEN $^{1,2}$, YANG YUAN ${ }^{2}$, TIANYING ZHANG ${ }^{2}$, BO XU $^{2}$, QING GAO $^{2}$ and TIANJUN GUAN ${ }^{2,3}$ \\ ${ }^{1}$ Department of Nephrology, Ningbo First Hospital, Ningbo, Zhejiang 315010; ${ }^{2}$ Department of Nephrology, Zhongshan Hospital, \\ Xiamen University; ${ }^{3}$ Department of Nephrology, Teaching Hospital of Fujian Medical University, \\ Xiamen, Fujian 361004, P.R. China
}

Received January 28, 2016; Accepted November 20, 2017

DOI: $10.3892 / \mathrm{ijmm} .2017 .3290$

\begin{abstract}
The apoptosis of tubular epithelial cells in diabetic nephropathy (DN) is commonly observed in human renal biopsies. Inflammation plays a key role in $\mathrm{DN}$, and pentosan polysulfate (PPS) has been shown to largely attenuate the inflammation of nephropathy in aging diabetic mice. p38 mitogen-activated protein kinase (p38 MAPK) plays a crucial role in tissue inflammation and cell apoptosis, and it is activated by hyperglycemia. In the present study, high glucose (HG)-treated human renal proximal tubular epithelial cells (HK-2) were used to examine the protective effects of PPS against HG-stimulated apoptosis and inflammation. The results of the study revealed that PPS markedly suppressed the $\mathrm{HG}$-induced reduction in cell viability. Incubation of HK-2 cells with HG activated the p38 MAPK pathway and, subsequently, as confirmed by western blot analysis and flow cytometry, increased cell apoptosis, which was blocked by PPS. In addition, PPS treatment significantly inhibited HG-stimulated p38 MAPK and nuclear factor- $\kappa \mathrm{B}$ activation, and reduced the production of pro-inflammatory cytokines, such as tumor necrosis factor- $\alpha$, interleukin (IL)-1 $\beta$ and IL-6. In conclusion, PPS ameliorates p38 MAPK-mediated renal cell apoptosis and inflammation. The anti-apoptotic actions and anti-inflammatory effects of PPS prompt further investigation of this compound as a promising therapeutic agent against DN.
\end{abstract}

\section{Introduction}

Diabetic nephropathy (DN) is the primary cause of end-stage renal disease (ESRD), and the leading cause of morbidity and mortality in diabetic patients (1). A number of pathways

Correspondence to: Dr Tianjun Guan, Department of Nephrology, Zhongshan Hospital, Xiamen University, 201 Hubin South Road, Xiamen, Fujian 361004, P.R. China

E-mail: guantianjun@aliyun.com

Key words: pentosan polysuflate, apoptosis, inflammation, p38 mitogen-activated protein kinase, HK-2 cells contribute to the progression of DN. Glomerular hyperfiltration, dysregulation of the renal vasculature, excessive oxidative stress, increased transforming growth factor (TGF)- $\beta$, activation of protein kinase $\mathrm{C}$ and the accumulation of advanced glycation end products (AGEs) may contribute to the pathogenesis of DN (2-6). Glomerular hypertrophy, mesangial cell proliferation, thickening of the glomerular basement membrane, extracellular matrix expansion and glomerular sclerosis are the pathological characteristics of DN. However, mounting evidence indicates that renal tubular cell injury also plays a key role in DN and may predict the declining renal function more efficiently compared with glomerular damage $(7,8)$. Chronic low-grade inflammation plays a key role in the progression and development of DN, and inflammation in the tubulointerstitial lesion is a crucial component of renal dysfunction $(9,10)$. Cell apoptosis is the process of normal cell death that activates cell responses to change the microenvironment, albeit immoderate apoptosis in DN may trigger pathological processes. The hyperglycemic state is an apoptosis-facilitating microenvironment. Apoptosis has been observed in human diabetic kidney biopsies, particularly in tubular cells (11), as well as HK-2 cells exposed to high glucose (HG) conditions $(12,13)$.

p38 mitogen-activated protein kinase (p38 MAPK) is a member of the MAPK family and is known to play a key role in inflammation and apoptosis. Activation of p38 MAPK has been demonstrated in renal biopsy specimens in a wide spectrum of human glomerulonephritis, and has been correlated with renal dysfunction and histopathological alterations (14). Previous findings demonstrated the key role of p38 MAPK in the progression and development of DN, and its suppression has been found to be a beneficial treatment strategy for DN (15-17). Pentosan polysulfate (PPS) is a semisynthetic sulfated polysaccharide that has been used for the treatment of interstitial cystitis (18). PPS treatment prevents the progression of DN in mice, and the underlying mechanism may be that PPS inhibits nuclear factor $(\mathrm{NF})-\kappa \mathrm{B}$ activation and inflammation stimulated by tumor necrosis factor (TNF)- $\alpha$, HG and AGEs (19).

However, the protective effects of PPS against HG-induced cell apoptosis and inflammation have not been fully elucidated. In the present study, the anti-apoptotic and anti-inflammatory 
effects of PPS on HK-2 cells were investigated, aiming to identify its protective mechanism and assess its clinical potential.

\section{Materials and methods}

Cell culture. HK-2 cells were obtained from the American Type Culture Collection (ATCC, Manassas, VA, USA). The cells were cultured in Dulbecco's modified Eagle's medium (DMEM) containing 10\% heat-inactivated fetal bovine serum (FBS), epidermal growth factor, and 1\% streptomycin-penicillin mixture in a $5 \% \mathrm{CO}_{2}$ incubator at $37^{\circ} \mathrm{C}$. After achieving 70-85\% confluence, the cells were growth-arrested to synchronize the cell growth for $24 \mathrm{~h}$ in FBS-free DMEM. The media were then changed to serum-free media with normal glucose $(\mathrm{NG})(5.5 \mathrm{mmol} / \mathrm{l})$ or $\mathrm{HG}(30 \mathrm{mmol} / \mathrm{l})$ at different time-points. PPS $(200 \mu \mathrm{g} / \mathrm{ml})$ and SB203580 $(10 \mu \mathrm{M})$ were added $2 \mathrm{~h}$ prior to $\mathrm{HG}$.

Measurement of cell viability. The viability of HK-2 cells was determined using a 3-(4,5-dimethylthiazol-2-yl)-2,5-diphenyltetrazolium bromide (MTT) Cell Proliferation Assay kit (American Type Culture Collection, Manassas, VA, USA). Briefly, HK-2 cells were grown at a density of $1 \times 10^{4}$ cells $/ \mathrm{ml}$ in 96-well culture plates in culture media with $5.5,15,25$, or $30 \mathrm{mmol} / \mathrm{lglucose}$, and maintained for up to $48 \mathrm{~h}$. PPS was administered at different concentrations (50, 100, 150 and $200 \mu \mathrm{g} / \mathrm{ml})$. A $10 \mu \mathrm{l}$ MTT reagent was added to each well and incubated at $37^{\circ} \mathrm{C}$ for $4 \mathrm{~h}$. The culture media with MTT reagent were then removed. The incorporated formazan crystals in the viable cells were dissolved with $100 \mu \mathrm{l}$ detergent reagent and the absorbance of each well was determined using a microplate reader (model 3550-UV; Bio-Rad, Tokyo, Japan) at a $540 \mathrm{~nm}$ wavelength.

Western blot analysis. Following treatment, the cells were lysed in RIPA buffer containing protease and phosphatase inhibitors. The cell protein was quantified with the bicinchoninic acid protein assay method with bovine serum albumin as the standard. The protein samples ( $40 \mu \mathrm{g} / \mathrm{lane})$ were subsequently separated with 10-15\% SDS-PAGE and electroblotted to polyvinylidene fluoride (PVDF) membranes (Bio-Rad, Hercules, CA, USA), which were blocked using 5\% fat-free milk for $2 \mathrm{~h}$ at $37^{\circ} \mathrm{C}$. Subsequently, the PVDF membranes were incubated overnight at $4^{\circ} \mathrm{C}$ with one of the monoclonal rabbit anti-human primary antibodies: p38 MAPK (1:1,000; cat. no. 14451), phospho-p38 MAPK (1:500; cat. no. 4092), caspase-3 (1:1,000; cat. no. 14220), cleaved caspase-3 (1:500; cat. no. 9654), Bcl-2 (1:500; cat. no. 4223), Bax (1:500; cat. no. 5023), NF-кB p65 (1:500; cat. no. 59674) and $\beta$-actin (1:2,000; cat. no. 12620) antibodies (all from Cell Signaling Technology, Inc., Danvers, MA, USA). Incubation with the secondary antibody $(1: 5,000)$ (Santa Cruz Biotechnology, Inc., Santa Cruz, CA, USA) was performed at room temperature for $1 \mathrm{~h}$. The blots were then visualized using a western blot analysis detection system (ECL Plus; GE Healthcare, Princeton, NJ, USA).

Flow cytometric analysis of apoptosis. The apoptotic rate of HK-2 cells was determined using a commercially available kit (Apoptosis Detection kit; BD Biosciences, San Jose, CA, USA) according to the manufacturer's instructions. Briefly, following administration of the different treatments,
HK-2 cells were collected and washed twice with cold PBS and then re-suspended in a volume of $200 \mu 11 \mathrm{X}$ binding buffer. Subsequently, the cells were incubated with $5 \mu$ l propidium iodide (PI) and $5 \mu 1$ fluorescein isothiocyanate (FITC) Annexin $\mathrm{V}$ at room temperature for $15 \mathrm{~min}$ in the dark. After the incubation period, $400 \mu 1$ of $1 \mathrm{X}$ binding buffer were added and results were calculated and analyzed in a FACScan flow cytometer and Cell software (BD Biosciences).

ELISA. The secreted pro-inflammatory cytokines TNF- $\alpha$, interleukin (IL)-1 $\beta$ and IL- 6 were analyzed in the supernatant using commercially available ELISA kits following the manufacturer's instructions. The absorbance at $492 \mathrm{~nm}$ was measured using a microplate reader (model 3550-UV; Bio-Rad).

Statistical analysis. Experiments were performed in triplicate and repeated three times. Values are presented as means \pm standard deviation. Analysis of variance was used for multiple comparisons among groups. GraphPad InStat version 5.0 statistical software (GraphPad Software, Inc., San Diego, CA, USA) was used to perform analyses. The results were defined as statistically significant when $\mathrm{P}<0.05$.

\section{Results}

PPS enhances cell viability in HG-treated cells. To test whether PPS treatment attenuated the HG-induced cytotoxicity, cell viability was determined at various levels of glucose (5-30 mmol/l) and PPS (50-200 $\mu \mathrm{g} / \mathrm{ml})$. The results demonstrated that HK-2 cells incubated with $30 \mathrm{mmol} / \mathrm{l}$ glucose exhibited evidently attenuated cell viability compared with the cells exposed to $5 \mathrm{mmol} / \mathrm{l}$ glucose. Treatment with $200 \mu \mathrm{g} / \mathrm{ml}$ PPS in the HG group markedly increased cell viability (Fig. 1). Therefore, PPS exerted a protective effect on HK-2 cells.

$H G$ increases the activity of p38 MAPK in HK-2 cells. The effect of HG on the activation of p38 MAPK in vitro was examined. HK-2 cells were incubated with HG at different time-points. The activity of phospho-p38 MAPK was analyzed using western blot analysis (Fig. 2A). HK-2 cells exposed to HG exhibited an increase of phospho-p38 MAPK in a time-dependent manner. The increase occurred at $6 \mathrm{~h}$ and was most prominent at $48 \mathrm{~h}$ (Fig. 2B).

PPS inhibits $H G$-stimulated p38 MAPK activation in $H K-2$ cells. To examine the effects of PPS on HG-stimulated p38 MAPK activation, HK-2 cells were treated with PPS. Compared with the NG group, incubation of HK-2 cells with HG for $48 \mathrm{~h}$ markedly increased the activity of p38 MAPK, which was significantly blocked by PPS (Fig. 3A and B). There was no evident change in $\mathrm{p} 38$ MAPK activation in HK-2 cells that were incubated with NG and were treated with PPS (Fig. 3B).

PPS prevents $H G$-stimulated apoptosis in $H K-2$ cells by inhibiting the activation of p38 MAPK. Previous findings have demonstrated that HG may increase apoptosis via the activation of p38 MAPK in HK-2 cells (20-22). Whether the p38 MAPK pathway is involved in the protective effects of PPS against HG-induced HK-2 cell apoptosis was also inves- 


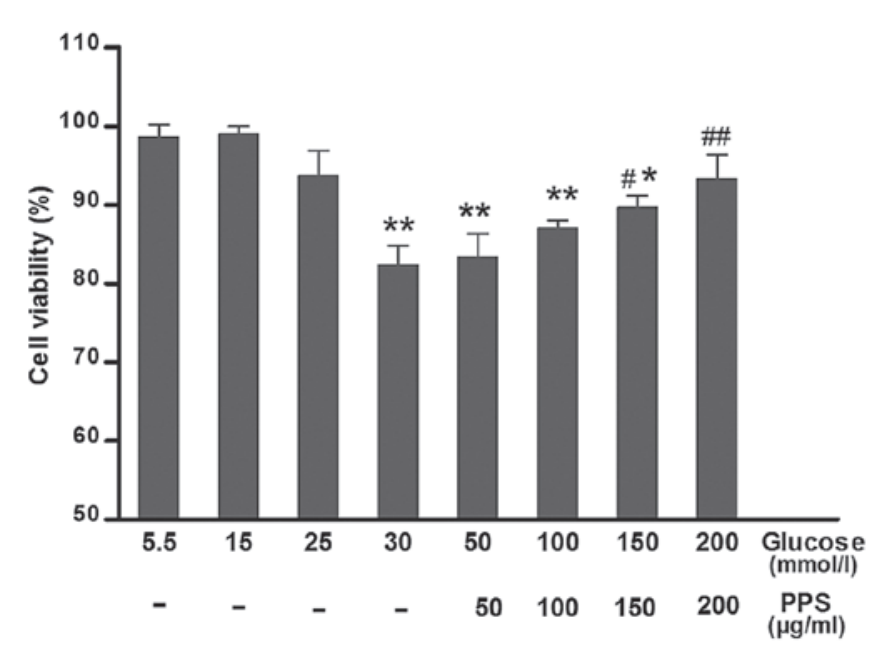

Figure 1. Cell viability. HK-2 cells were treated with 50-200 $\mu \mathrm{g} / \mathrm{ml}$ PPS and assessed using the MTT assay. Values are presented as means \pm standard deviation of at least three determinations. ${ }^{~} \mathrm{P}<0.05,{ }^{* * *} \mathrm{P}<0.01$ compared with $5 \mathrm{mmol} / 1$ glucose treatment. ${ }^{\#} \mathrm{P}<0.05,{ }^{\# /} \mathrm{P}<0.01$ compared with $30 \mathrm{mmol} / \mathrm{l}$ glucose treatment. PPS, pentosan polysulfate.
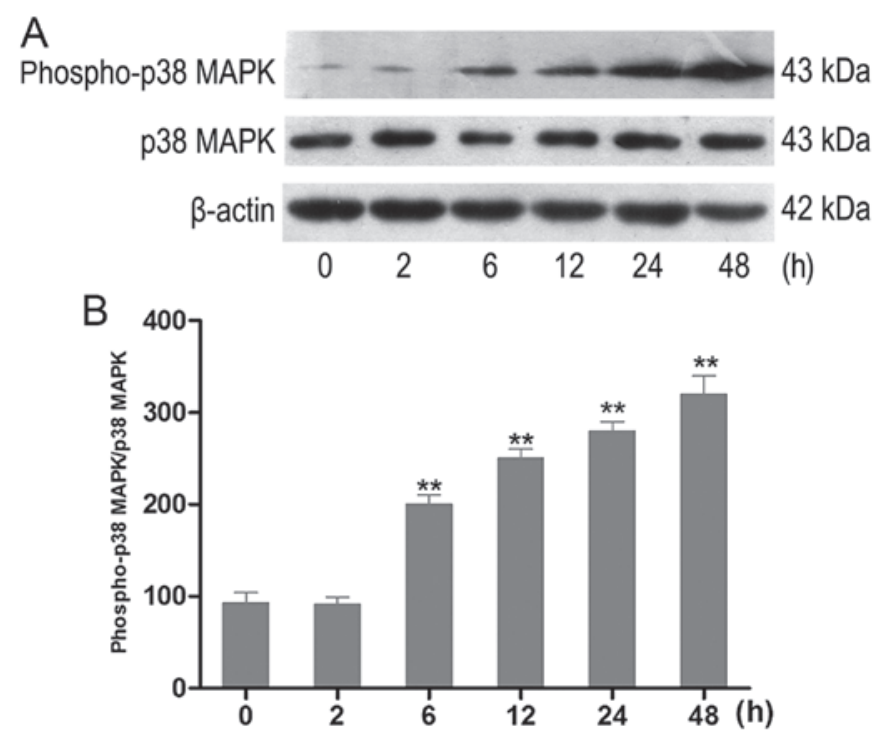

Figure 2. Effect of HG treatment on the expression of phospho-p38 MAPK in HK-2 cells. (A) The expression levels of p38 MAPK and phospho-p38 MAPK in cultured HK-2 cells exposed to $\mathrm{HG}(30 \mathrm{mmol} / \mathrm{l})$ were examined using western blot analysis. Representative western blots of phospho-p38 MAPK in experimental groups at various time-points $(\mathrm{n}=6)$. (B) Densitometric analysis of western blots. Data are presented as the means from triplicate determinations (means \pm standard deviation) indicated by the vertical bars ${ }^{(* *} \mathrm{P}<0.01$ vs. control). HG, high glucose; p38 MAPK, p38 mitogen-activated protein kinase.

tigated. Cell apoptosis was examined after $48 \mathrm{~h}$ of treatment with HG. Incubation with HG caused a marked increase of the $\mathrm{Bax} / \mathrm{Bcl}-2$ ratio and the cleaved caspase-3/caspase-3 ratio in HK-2 cells, which was significantly attenuated by PPS and SB203580 (Fig. 4A and B). Flow cytometry was used to analyze the apoptosis of HK-2 cells. Higher HK-2 cell apoptosis was induced by HG compared with NG, which was improved by PPS or SB203580, as verified by Annexin V-FITC and PI staining (Fig. 4C and D). In addition, it was determined whether the combination of PPS and SB20358 exerted a synergistic effect on HG-stimulated apoptosis in HK-2 cells. The results

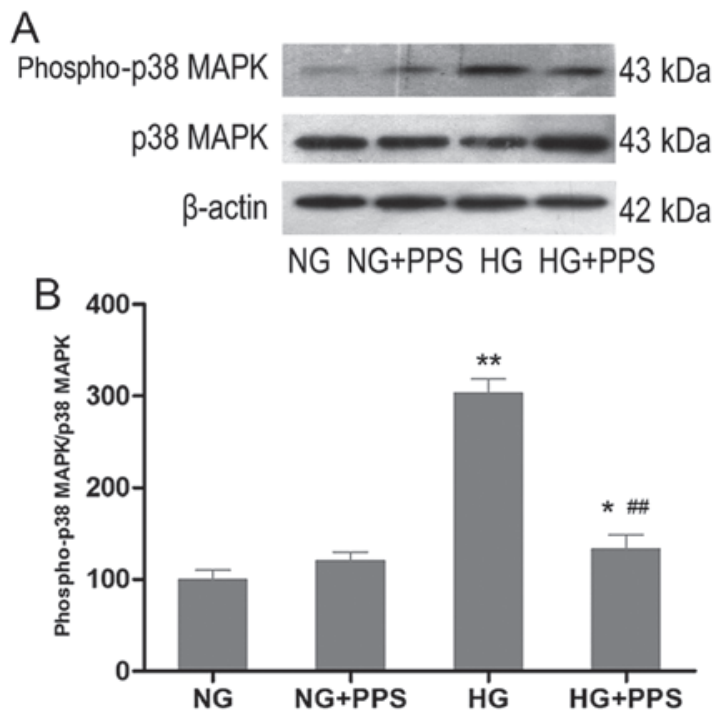

Figure 3. Effect of PPS on the expression of HG-stimulated phospho-p38 MAPK in HK-2 cells. (A) HK-2 cells were grown in HG and NG in the absence or presence of PPS for $48 \mathrm{~h}$. Phospho-p38 MAPK expression was determined by western blot analysis. (B) Densitometric scan analysis for western blotting. NG: $5.5 \mathrm{mmol} / 1 \mathrm{D}$-glucose; NG + PPS: $5.5 \mathrm{mmol} / 1 \mathrm{D}$-glucose plus $200 \mu \mathrm{g} / \mathrm{ml} \mathrm{PPS}$; HG: $30 \mathrm{mmol} / 1 \mathrm{D}$-glucose; and HG + PPS: $30 \mathrm{mmol} / \mathrm{l} \mathrm{D}$-glucose plus $200 \mu \mathrm{g} / \mathrm{ml}$ PPS. Data are presented as the means from triplicate determinations (means \pm standard deviation) indicated by the vertical bars $\left({ }^{*} \mathrm{P}<0.05\right.$, ${ }^{* *} \mathrm{P}<0.01$ vs. NG and ${ }^{\# \#} \mathrm{P}<0.01$ vs. HG). PPS, pentosan polysulfate; HG, high glucose; NG, normal glucose; p38 MAPK, p38 mitogen-activated protein kinase.

demonstrated that this combination resulted in a mild increase of the $\mathrm{Bax} / \mathrm{Bcl}-2$ and cleaved caspase-3/caspase-3 ratios compared with PPS or SB203580 alone, although the difference was not statistically significant $(\mathrm{P}<0.05$; Fig. $4 \mathrm{E}$ and $\mathrm{F})$. Therefore, suppression of the p38 MAPK pathway blocked HG-stimulated apoptosis in HK-2 cells.

PPS inhibits HG-induced inflammatory response in HK-2 cells. Our previous results demonstrated that PPS directly affects the inflammatory action of TNF- $\alpha$ in proximal tubular cells (19). The action of PPS was also assessed. Treatment with HG stimulated a marked increase in the activation of the inflammatory response, $\mathrm{p} 38 \mathrm{MAPK}$ and NF- $\mathrm{kB}$, as indicated by the increased levels of phospho-p38 MAPK and NF- $\mathrm{kB}$ p65 in the HG vs. the NG group. Compared with the HG group, PPS treatment significantly inhibited this $\mathrm{HG}$-stimulated NF- $\mathrm{\kappa B}$ and p38 MAPK activation in the HG + PPS group (Fig. 5A and B). However, no significant change was observed in the activation of NF- $\kappa$ B and p38 MAPK between the NG and NG + PPS groups (Fig 5B), suggesting that PPS does not exert any toxic effect on normal HK-2 cells. Compared with the NG group, the secretion of the pro-inflammatory cytokines TNF- $\alpha$, IL-1 $\beta$ and IL- 6 was evidently increased in the HG group, which was in agreement with the activation of NF- $\mathrm{kB}$ and p38 MAPK (Fig. 6). Compared with the HG group, PPS treatment markedly reduced HG-stimulated pro-inflammatory cytokine production in the HG + PPS group (Fig. 6).

\section{Discussion}

In the present study, the anti-apoptotic effects and anti-inflammatory properties of PPS were evaluated using HG-treated 
A

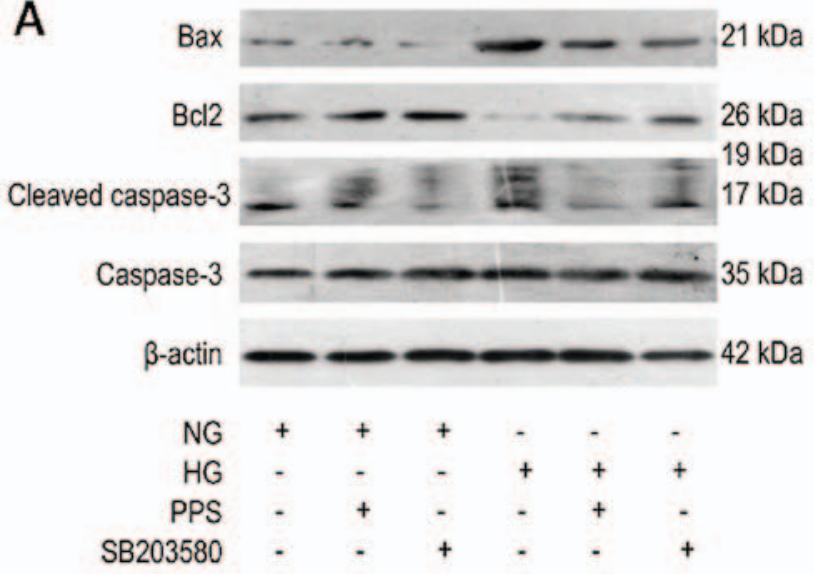

C
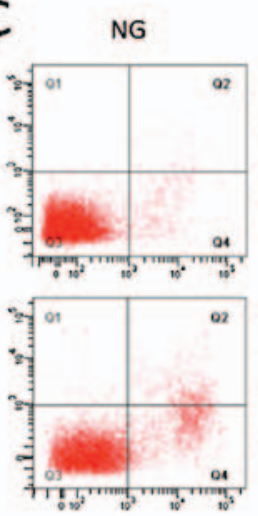

HG

E

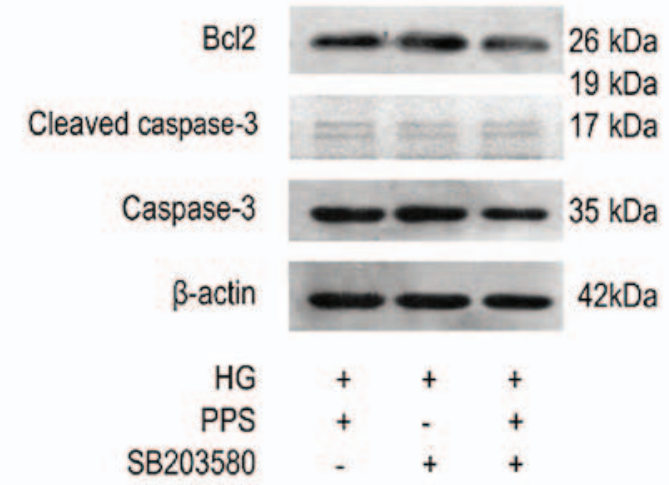

HG+SB203580

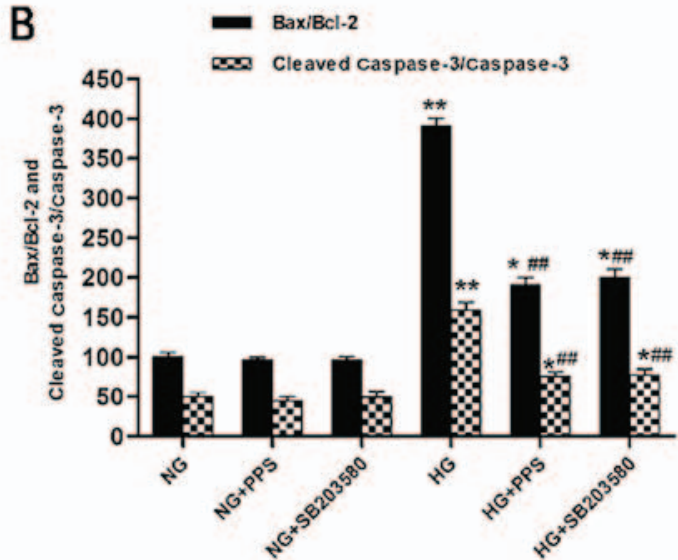

D
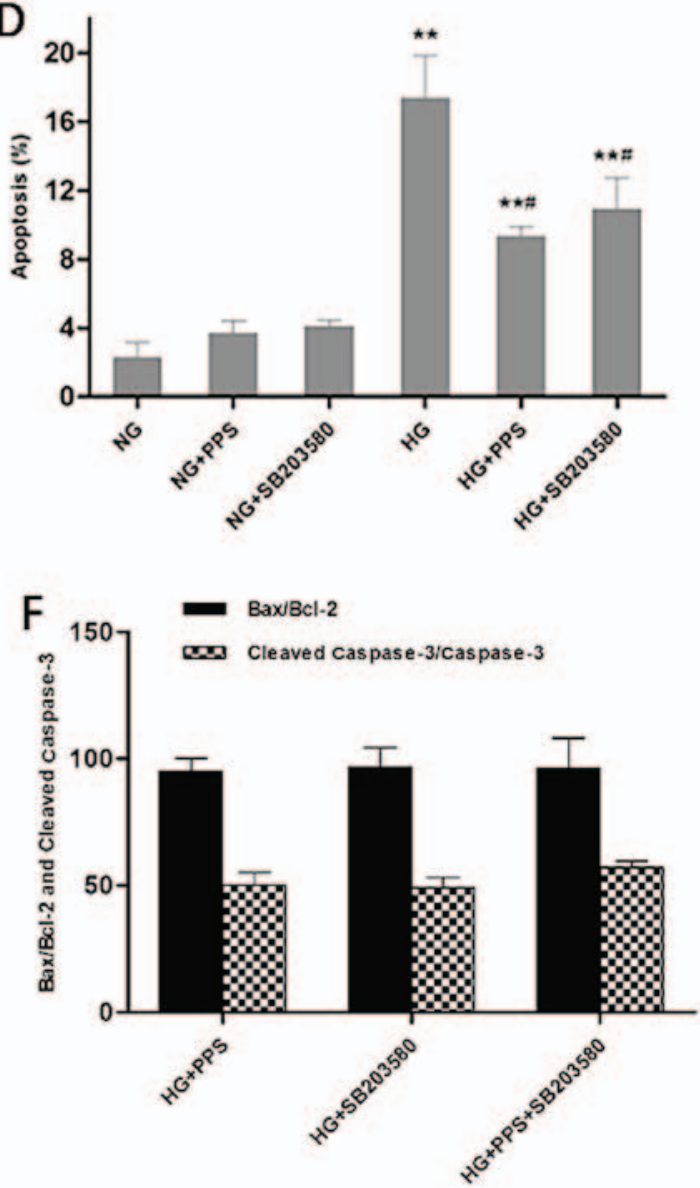

Figure 4. Effect of PPS or SB2035 on HG-induced apoptosis in HK-2 cells. (A) HK-2 cells were grown in HG and NG in the absence or presence of PPS or SB203580 for $48 \mathrm{~h}$. The expression levels of caspase-3, cleaved caspase-3, Bax, Bcl-2 and $\beta$-actin were determined using western blot analysis. (B) Densitometric analysis for western blot analysis. (C) Apoptosis of HK-2 cells was determined by flow cytometry. (D) Analysis of apoptotic rate using flow cytometry. (E) Effects of PPS and SB203580 on the expression of caspase-3, cleaved caspase-3, Bax, Bcl-2 and $\beta$-actin were determined using western blot analysis. (F) Densitometric analysis for western blotting. NG: 5.5 mmol/1 D-glucose; NG + PPS: 5.5 mmol/1 D-glucose plus $200 \mu \mathrm{g} / \mathrm{ml}$ PPS; NG + SB203580: $5.5 \mathrm{mmol} / 1$ D-glucose plus $10 \mu \mathrm{M}$ SB203580; HG: 30 mmol/1 D-glucose; HG + PPS: 30 mmol/l D-glucose plus $200 \mu \mathrm{g} / \mathrm{ml}$ PPS; HG + SB203580: 30 mmol/1 D-glucose plus $10 \mu \mathrm{M}$ SB203580; and HG + PPS + SB203580: $30 \mathrm{mmol} / 1 \mathrm{M}$ D-glucose plus $200 \mu \mathrm{g} / \mathrm{ml}$ PPS plus $10 \mu \mathrm{M}$ SB203580. Experiments were repeated at least three times, and the results are presented as the mean \pm standard deviation. ${ }^{*} \mathrm{P}<0.05$ and ${ }^{* *} \mathrm{P}<0.01$ vs. NG; ${ }^{*} \mathrm{P}<0.01$ vs. HG; ${ }^{\# \#} \mathrm{P}<0.01$ vs. HG. PPS, pentosan polysulfate; HG, high glucose; NG, normal glucose.

HK-2 cells. The results revealed that PPS treatment ameliorated apoptosis and inflammation by inhibiting the activation of p38 MAPK stimulated by HG. Whether PPS treatment attenuated the HG-induced cytotoxicity was also investigated by assessing the nephroprotective effect of PPS in terms of cell viability. The results demonstrated that PPS markedly enhanced cell viability, suggesting that PPS protects against HG-induced cytotoxicity.

Accumulating evidence indicates that renal tubular injury plays a critical role in the pathogenesis of human and animal DN (7,23). Apoptosis is associated with the progression of human DN $(11,24)$. The apoptosis-associated marker cleaved 


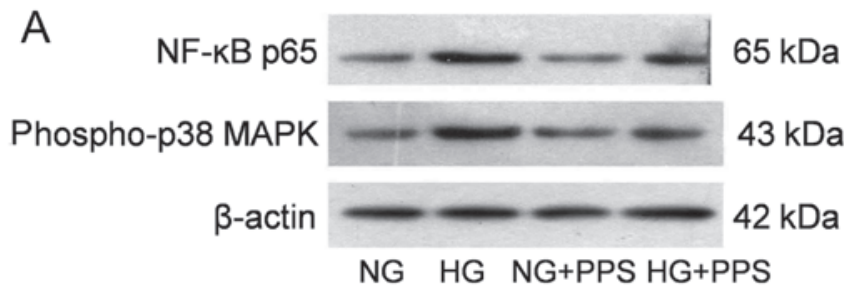

B

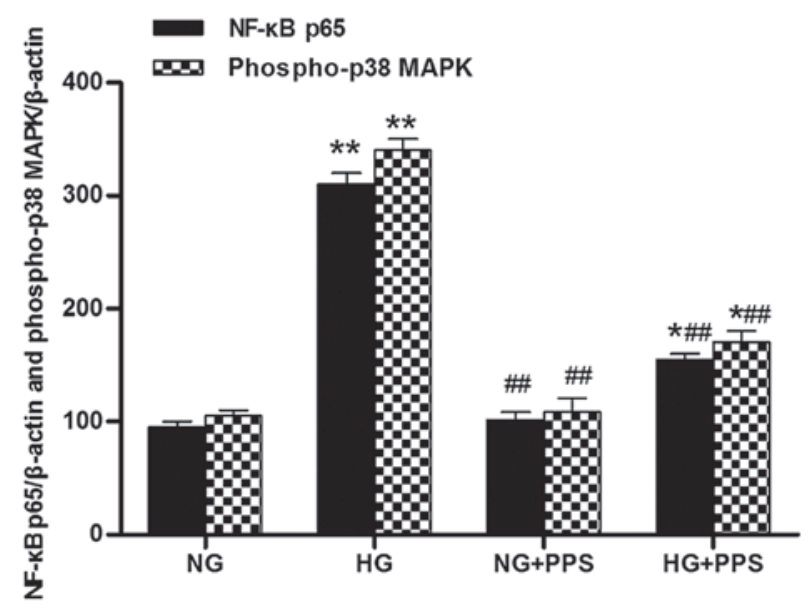

Figure 5. Effects of PPS on phospho-p38 MAPK and NF-кB p65 expression in cultured HK-2 cells. (A) Western blot analysis of phospho-p38 MAPK and NF- $\mathrm{KB}$ p65 activities in HK-2 cells. (B) Densitometric data of protein analysis. NG: $5.5 \mathrm{mmol} / \mathrm{l}$ D-glucose; HG: $30 \mathrm{mmol} / \mathrm{l} \mathrm{D}$-glucose; $\mathrm{NG}+\mathrm{PPS}$ : $5.5 \mathrm{mmol} / 1 \mathrm{D}$-glucose plus $200 \mu \mathrm{g} / \mathrm{ml} \mathrm{PPS}$; and $\mathrm{HG}+\mathrm{PPS}$ : $30 \mathrm{mmol} / \mathrm{l}$ D-glucose plus $200 \mu \mathrm{g} / \mathrm{ml}$ PPS. Data are presented as the means from triplicate determinations (means \pm standard deviation) indicated by the vertical bars ( $\mathrm{P}<0.05,{ }^{* *} \mathrm{P}<0.01$ vs. NG and ${ }^{\# \# /} \mathrm{P}<0.01$ vs. HG). PPS, pentosan polysulfate; 338 MAPK, p38 mitogen-activated protein kinase; NF-кB, nuclear factor- $\mathrm{\kappa B}$; NG, normal glucose, $\mathrm{HG}$, high glucose.

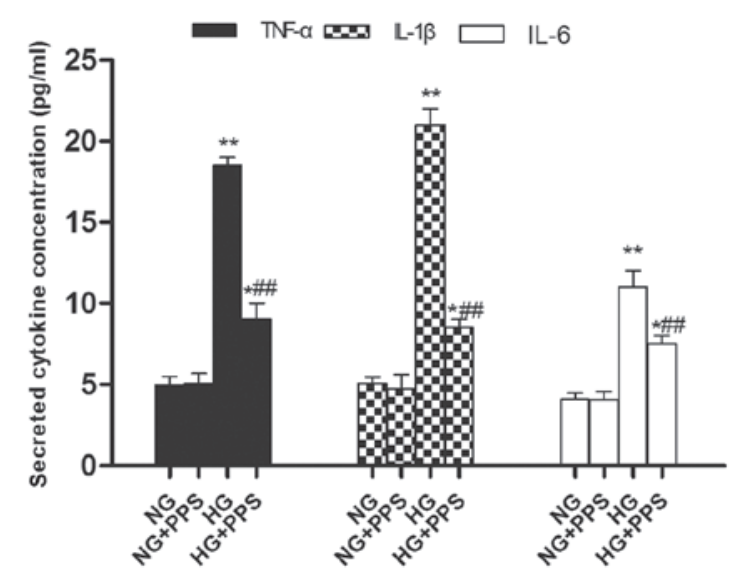

Figure 6. Effects of PPS on pro-inflammatory cytokine levels (TNF- $\alpha$, IL-1 $\beta$ and IL-6) in HK-2 cells. NG: $5.5 \mathrm{mmol} / 1 \mathrm{D}$-glucose; HG: $30 \mathrm{mmol} / 1$ D-glucose; NG + PPS: $5.5 \mathrm{mmol} / 1 \mathrm{D}$-glucose plus $200 \mu \mathrm{g} / \mathrm{ml}$ PPS; and HG + PPS: $30 \mathrm{mmol} / 1 \mathrm{D}$-glucose plus $200 \mu \mathrm{g} / \mathrm{ml}$ PPS. Each bar shows the mean \pm standard deviation from three independent experiments performed in triplicate $\left(" \mathrm{P}<0.05,{ }^{* *} \mathrm{P}<0.01\right.$ vs. NG and ${ }^{\# \#} \mathrm{P}<0.01$ vs. HG). PPS, pentosan polysulfate; TNF- $\alpha$, tumor necrosis factor- $\alpha$; IL, interleukin; NG, normal glucose, $\mathrm{HG}$, high glucose.

caspase-3/caspase-3 and $\mathrm{Bax} / \mathrm{Bcl}-2$ protein levels were investigated, and PPS was found to modulate these protein levels, indicating that PPS treatment suppressed HG-stimulated apoptosis in HK-2 cells. The present study confirmed that the anti-apoptotic properties of PPS required inhibition of the p38 MAPK pathways. Our results are consistent with those of previous studies whereby HG and hyperglycemia induced renal tubular cell apoptosis primarily through regulating the $\mathrm{Bcl}-2 /$ caspase/poly(ADP-ribose) polymerase pathway $(12,13,20,25)$. p38 MAPK is a member of the MAPK superfamily, including JNK, ERK1/2 and ERK5, and it plays a key role in renal cell death and the development of DN. It has been demonstrated that phosphorylated p38 MAPK is expressed mainly in diabetic tubules, which is associated with tubular lesions (26), and coincides with the localization of TGF- $\beta$ (27), indicating the role of p38 MAPK in TGF- $\beta$-mediated renal fibrosis. Similarly, previous findings demonstrated the expression of activated p38 MAPK and the production of fibrotic and inflammatory markers, such as TGF- $\beta$, collagen III and TNF- $\alpha$, in diabetic mouse kidneys (21). Accumulating evidence indicates that activation of the p38 MAPK signaling pathway induces renal tubular cell apoptosis, whereas suppressing it significantly ameliorates tubular cell apoptosis and renal dysfunction $(20,28)$. In the present study, PPS, which exerted its effects through downregulating p38 MAPK activation, may provide a therapeutic alternative to prevent p38 MAPK-mediated DN. In the present study, the p38 MAPK inhibitor SB203580 was used as the positive control to investigate the role of PPS in HG-stimulated apoptosis of HK-2 cells. The findings revealed that, while administration of PPS or SB203580 alone attenuated HG-induced HK-2 cell apoptosis, combination treatment resulted in a mild but not statistically significant increase, indicating a dose-dependent cytotoxic action of the inhibitor.

Although numerous factors contribute to the pathogenesis of DN, it is increasingly considered as an inflammatory disease $(9,10)$. Infiltration by macrophages and lymphocytes and the overproduction of pro-inflammatory chemokines and cytokines are observed in renal diabetic tissues, which promote further inflammation in the kidney (29-33). Monocyte chemoattractant protein-1 (MCP-1) promotes the recruitment of macrophages and upregulates the production of pro-inflammatory cytokines (34). Diabetic db/db mice and streptozotocin-stimulated diabetic mice, which lack the MCP-1 gene, are resistant to DN $(35,36)$. Intercellular adhesion molecule-1 (ICAM-1) facilitates the infiltration of leukocytes into diabetic kidneys (37). Diabetic ICAM-1-deficient mice exhibit amelioration of urinary albumin excretion, glomerular hypertrophy and renal fibrosis, which are correlated with a reduction in macrophage accumulation $(38,39) . \mathrm{NF}-\kappa \mathrm{B}$ is one of the crucial transcription factors involved in the progression of DN (40). In response to inflammatory and stressful stimuli, p38 MAPK is activated by upstream kinases and MAPK3/6, and is then translocated to the nucleus, modulating the activation and expression of various genes, including NF- $\kappa \mathrm{B}(15,17,37)$, pro-inflammatory cytokines (TNF- $\alpha$, IL- 6 and IL-1 $\beta$ ) (41), chemokines (chemokine ligand 2), cell adhesion molecules (ICAM-1) and growth factors (vascular endothelial growth factor, TGF- $\beta$ and cytoplasmic transmembrane growth factor) $(5,42,43)$. Our findings confirmed that PPS treatment significantly prevented $\mathrm{NF}-\kappa \mathrm{B}$ and p38 MAPK activation in HG-treated HK-2 cells. Furthermore, the production of pro-inflammatory cytokines (TNF- $\alpha$, IL-6 and IL-1 $\beta$ ) was markedly alleviated by PPS treatment. The results are consistent with those of our previous 
findings, which demonstrated that PPS inhibited the inflammation mediated by TNF- $\alpha$, HG and AGEs (19). It is hypothesized that PPS blocked the activation of $N F-\kappa B$ and reduced the expression of pro-inflammatory cytokines by suppressing the p38 MAPK pathway. It has been reported that apoptosis may be induced by $\mathrm{HG}$ through a mechanism associated with inflammation (44). Collectively, based on the present findings and previous results, the anti-inflammatory properties of PPS are considered to be another possible mechanism underlying its anti-apoptotic effects.

In conclusion, the present findings demonstrated that PPS treatment attenuates HG-stimulated apoptosis and inflammation in HK-2 cells through inhibition of p38 MAPK activation, thereby preventing DN. The protective effect of PPS in HK-2 cells is correlated with suppression of the p38 MAPK signaling pathway. The present study provides experimental evidence to investigate the possible use of PPS as a promising therapeutic agent against $\mathrm{DN}$.

\section{Acknowledgements}

The present study was supported by the Xiamen Municipal Bureau of Science and Technology (grant no. 3502Z20134015), the Natural Science Foundation of Fujian Province (grant no. 2015J01532) and the projects of the Medical and Health Technology Program in Zhejiang Province (grant no. 2018KY679).

\section{References}

1. Gross JL, de Azevedo MJ, Silveiro SP, Canani LH, Caramori ML and Zelmanovitz T: Diabetic nephropathy: Diagnosis, prevention, and treatment. Diabetes Care 28: 164-176, 2005.

2. Tan AL, Forbes JM and Cooper ME: AGE, RAGE, and ROS in diabetic nephropathy. Semin Nephrol 27: 130-143, 2007.

3. Magee GM, Bilous RW, Cardwell CR, Hunter SJ, Kee F and Fogarty DG: Is hyperfiltration associated with the future risk of developing diabetic nephropathy? A meta-analysis. Diabetologia 52: 691-697, 2009.

4. Nishikawa T, Edelstein D, Du XL, Yamagishi S, Matsumura T, Kaneda Y, Yorek MA, Beebe D, Oates PJ, Hammes HP, et al: Normalizing mitochondrial superoxide production blocks three pathways of hyperglycaemic damage. Nature 404: 787-790, 2000.

5. Navarro-González JF and Mora-Fernández C: The role of inflammatory cytokines in diabetic nephropathy. J Am Soc Nephrol 19: 433-442, 2008.

6. Noh H and King GL: The role of protein kinase C activation in diabetic nephropathy. Kidney Int Suppl 72 (Suppl): S49-S53, 2007.

7. Magri CJ and Fava S: The role of tubular injury in diabetic nephropathy. Eur J Intern Med 20: 551-555, 2009.

8. Gilbert RE and Cooper ME: The tubulointerstitium in progressive diabetic kidney disease: More than an aftermath of glomerular injury? Kidney Int 56: 1627-1637, 1999.

9. Mora $\mathrm{C}$ and Navarro JF: Inflammation and diabetic nephropathy. Curr Diab Rep 6: 463-468, 2006.

10. Tuttle KR: Linking metabolism and immunology: Diabetic nephropathy is an inflammatory disease. J Am Soc Nephrol 16 $1537-1538,2005$.

11. Kumar D, Robertson S and Burns KD: Evidence of apoptosis in human diabetic kidney. Mol Cell Biochem 259: 67-70, 2004.

12. Verzola D, Bertolotto MB, Villaggio B, Ottonello L, Dallegri F, Salvatore F, Berruti V, Gandolfo MT, Garibotto G and Deferrari G: Oxidative stress mediates apoptotic changes induced by hyperglycemia in human tubular kidney cells. J Am Soc Nephrol 15 (Suppl 1): S85-S87, 2004.

13. Verzola D, Bertolotto MB, Villaggio B, Ottonello L, Dallegri F, Frumento G, Berruti V, Gandolfo MT, Garibotto G and Deferran G: Taurine prevents apoptosis induced by high ambient glucose in human tubule renal cells. J Investig Med 50: 443-451, 2002.
14. Stambe C, Nikolic-Paterson DJ, Hill PA, Dowling J and Atkins RC: p38 mitogen-activated protein kinase activation and cell localization in human glomerulonephritis: Correlation with renal injury. J Am Soc Nephrol 15: 326-336, 2004.

15. Adhikary L, Chow F, Nikolic-Paterson DJ, Stambe C, Dowling J, Atkins RC and Tesch GH: Abnormal p38 mitogen-activated protein kinase signalling in human and experimental diabetic nephropathy. Diabetologia 47: 1210-1222, 2004.

16. Chen H, Brahmbhatt S, Gupta A and Sharma AC: Duration of streptozotocin-induced diabetes differentially affects p38-mitogen-activated protein kinase (MAPK) phosphorylation in renal and vascular dysfunction. Cardiovasc Diabetol 4: 3, 2005.

17. Du Y, Tang J, Li G, Berti-Mattera L, Lee CA, Bartkowski D, Gale D, Monahan J, Niesman MR, Alton G, et al: Effects of p38 MAPK inhibition on early stages of diabetic retinopathy and sensory nerve function. Invest Ophthalmol Vis Sci 51: 2158-2164, 2010.

18. Nickel JC,Barkin J,Forrest J,MosbaughPG,Hernandez-Graulau J, Kaufman D, Lloyd K, Evans RJ, Parsons CL and Atkinson LE; Elmiron Study Group: Randomized, double-blind, dose-ranging study of pentosan polysulfate sodium for interstitial cystitis. Urology 65: 654-658, 2005.

19. Wu J, Guan TJ, Zheng S, Grosjean F, Liu W, Xiong H, Gordon R, Vlassara H, Striker GE and Zheng F: Inhibition of inflammation by pentosan polysulfate impedes the development and progression of severe diabetic nephropathy in aging C57B6 mice. Lab Invest 91: 1459-1471, 2011.

20. Wu H, Shi Y, Deng X, Su Y, Du C, Wei J, Ren Y, Wu M, Hou Y and Duan H: Inhibition of c-Src/p38 MAPK pathway ameliorates renal tubular epithelial cells apoptosis in $\mathrm{db} / \mathrm{db}$ mice. Mol Cell Endocrinol 417: 27-35, 2015.

21. Rane MJ, Song Y, Jin S, Barati MT, Wu R, Kausar H, Tan Y, Wang Y, Zhou G, Klein JB, et al: Interplay between Akt and p38 MAPK pathways in the regulation of renal tubular cell apoptosis associated with diabetic nephropathy. Am J Physiol Renal Physiol 298: F49-F61, 2010.

22. Iwayama $\mathrm{H}$ and Ueda $\mathrm{N}$ : Role of mitochondrial Bax, caspases, and MAPKs for ceramide-induced apoptosis in renal proximal tubular cells. Mol Cell Biochem 379: 37-42, 2013.

23. Blantz RC and Singh P: Glomerular and tubular function in the diabetic kidney. Adv Chronic Kidney Dis 21: 297-303, 2014.

24. Baba K, Minatoguchi S, Sano H, Kagawa T, Murata I, Takemura G, Hirano T, Ohashi H, Takemura M, Fujiwara T, et al: Involvement of apoptosis in patients with diabetic nephropathy: A study on plasma soluble Fas levels and pathological findings. Nephrology (Carlton) 9: 94-99, 2004.

25. Habib SL: Diabetes and renal tubular cell apoptosis. World J Diabetes 4: 27-30, 2013.

26. Sakai N, Wada T, Furuichi K, Iwata Y, Yoshimoto K, Kitagawa K, Kokubo S, Kobayashi M, Hara A, Yamahana J, et al: Involvement of extracellular signal-regulated kinase and p38 in human diabetic nephropathy. Am J Kidney Dis 45: 54-65, 2005.

27. Fujita H, Omori S, Ishikura K, Hida M and Awazu M: ERK and p38 mediate high-glucose-induced hypertrophy and TGF-beta expression in renal tubular cells. Am J Physiol Renal Physiol 286: F120-F126, 2004.

28. Bocanegra V, Gil Lorenzo AF, Cacciamani V, Benardón ME, Costantino VV and Vallés PG: RhoA and MAPK signal transduction pathways regulate NHE1-dependent proximal tubule cell apoptosis after mechanical stretch. Am J Physiol Renal Physiol 307: F881-F889, 2014.

29. Galkina E and Ley K: Leukocyte recruitment and vascular injury in diabetic nephropathy. J Am Soc Nephrol 17: 368-377, 2006.

30. Chow F, Ozols E, Nikolic-Paterson DJ, Atkins RC and Tesch GH: Macrophages in mouse type 2 diabetic nephropathy: Correlation with diabetic state and progressive renal injury. Kidney Int 65: 116-128, 2004.

31. Sassy-Prigent C, Heudes D, Mandet C, Bélair MF, Michel O, Perdereau B, Bariéty J and Bruneval P: Early glomerular macrophage recruitment in streptozotocin-induced diabetic rats. Diabetes 49: 466-475, 2000.

32. Furuta T, Saito T, Ootaka T, Soma J, Obara K, Abe K and Yoshinaga K: The role of macrophages in diabetic glomerulosclerosis. Am J Kidney Dis 21: 480-485, 1993.

33. Bohle A, Wehrmann M, Bogenschütz O, Batz C, Müller CA and Müller GA: The pathogenesis of chronic renal failure in diabetic nephropathy. Investigation of 488 cases of diabetic glomerulosclerosis. Pathol Res Pract 187: 251-259, 1991.

34. Viedt C and Orth SR: Monocyte chemoattractant protein-1 (MCP-1) in the kidney: Does it more than simply attract monocytes? Nephrol Dial Transplant 17: 2043-2047, 2002. 
35. Chow FY, Nikolic-Paterson DJ, Ozols E, Atkins RC, Rollin BJ and Tesch GH: Monocyte chemoattractant protein-1 promotes the development of diabetic renal injury in streptozotocin-treated mice. Kidney Int 69: 73-80, 2006.

36. Chow FY, Nikolic-Paterson DJ, Ma FY, Ozols E, Rollins BJ and Tesch GH: Monocyte chemoattractant protein-1-induced tissue inflammation is critical for the development of renal injury but not type 2 diabetes in obese $\mathrm{db} / \mathrm{db}$ mice. Diabetologia 50 : 471-480, 2007.

37. Lim AK and Tesch GH: Inflammation in diabetic nephropathy. Mediators Inflamm 2012: 146154, 2012.

38. Chow FY, Nikolic-Paterson DJ, Ozols E, Atkins RC and Tesch GH: Intercellular adhesion molecule-1 deficiency is protective against nephropathy in type 2 diabetic $\mathrm{db} / \mathrm{db}$ mice. $\mathrm{J}$ Am Soc Nephrol 16: 1711-1722, 2005

39. Okada S, Shikata K, Matsuda M, Ogawa D, Usui H, Kido Y, Nagase R, Wada J, Shikata Y and Makino H: Intercellular adhesion molecule-1-deficient mice are resistant against renal injury after induction of diabetes. Diabetes 52: 2586-2593, 2003.

40. Sanchez AP and Sharma K: Transcription factors in the pathogenesis of diabetic nephropathy. Expert Rev Mol Med 11: e13, 2009 .
41. Saklatvala J: The p38 MAP kinase pathway as a therapeutic target in inflammatory disease. Curr Opin Pharmacol 4: 372-377, 2004.

42. Mezzano S, Aros C, Droguett A, Burgos ME, Ardiles L, Flores C, Schneider H, Ruiz-Ortega M and Egido J: NF-kappaB activation and overexpression of regulated genes in human diabetic nephropathy. Nephrol Dial Transplant 19: 2505-2512, 2004.

43. Yang B, Hodgkinson A, Oates PJ, Millward BA and Demaine AG: High glucose induction of DNA-binding activity of the transcription factor NFkappaB in patients with diabetic nephropathy. Biochim Biophys Acta 1782: 295-302, 2008.

44. Lewko B and Stepinski J: Hyperglycemia and mechanical stress: Targeting the renal podocyte. J Cell Physiol 221: 288-295, 2009.

This work is licensed under a Creative Commons Attribution-NonCommercial-NoDerivatives 4.0 International (CC BY-NC-ND 4.0) License. 